\title{
The WISDOM of inhaled corticosteroids in COPD
}

\author{
David M G Halpin, ${ }^{1}$ Jennifer K Quint ${ }^{2}$
}

Current national and international guidelines recommend the use of inhaled corticosteroids (ICS) in addition to long-acting bronchodilators in people with more severe COPD to reduce the risk of exacerbations. Opinions on the benefits and role of ICS in COPD have changed considerably over the last 25 years. In the 1980 s, they were widely used in Europe by extrapolation from their role in asthma. Indeed, it was thought that they might have long-term disease modifying potential and the ISOLDE study was undertaken to investigate this. ${ }^{1}$ ISOLDE showed no overall effect on the rate of decline in $\mathrm{FEV}_{1}$, but did for the first time raise the possibility that ICS had an effect on the occurrence of exacerbations.

Perhaps surprisingly, some long-acting bronchodilators were also found to reduce the risk of moderate and severe exacerbations compared with placebo. In a meta-analysis, this reduction in severe exacerbations requiring hospitalisation was over $25 \%$ in the long-acting $\beta$ agonist (LABA) group compared with placebo. $^{2}$ Some evidence suggests that long-acting antimuscarinics (LAMAs) are even more effective than LABAs at reducing exacerbations compared with placebo. ${ }^{3} 4$

Subsequently, studies investigated the effect of combinations of ICS with LABA bronchodilators and showed that the rate of exacerbations was reduced by both ICS and LABA but that the combination was more effective. ${ }^{5}$ The effect appeared to be most marked in people with an $\mathrm{FEV}_{1}$ less than $50 \%$ predicted. Recognition of the importance of exacerbations as key events in the course of COPD was also growing at this time, with studies showing that they were key determinants of health status and associated with a faster decline in lung function. Both from a patient and a health service perspective, prevention of exacerbations became a key objective of COPD management.

Unlike asthma management, COPD pharmacotherapy has largely been based

\footnotetext{
${ }^{1}$ Royal Devon \& Exeter Hospital, Exeter, UK;

${ }^{2}$ Department of NCDE, London School of Hygiene and Tropical Medicine, London, UK
}

Correspondence to Professor David M G Halpin, Royal Devon \& Exeter Hospital, Barrack Road, Exeter EX2 5DW, UK; d.halpin@nhs.net on the cumulative addition of drugs of different pharmacological classes, reflecting the progressive nature of the condition and its heterogeneity. The National Institute of Health and Care Excellence COPD guideline does recommend stopping therapy if it is ineffective. ${ }^{6}$ The challenge for exacerbation prevention therapy is assessing on an individual patient basis whether it has been effective in preventing an exacerbation or not: even if the patients continue to have exacerbations, they may have had more if they had not been on the therapy.

As part of the design of some of the studies assessing the effects of ICS patients had existing ICS therapy withdrawn prior to randomisation and it appeared that this was associated with an increased tendency to exacerbate. ${ }^{7}$ Similarly, a Dutch study designed to investigate the effects of withdrawing ICS therapy also showed it was associated with the occurrence of exacerbations as well as a deterioration in lung function and worsening breathlessness. ${ }^{8}$

The evidence of benefit and the small risk of destabilisation in patients whose ICS therapy is withdrawn has to be reconciled with growing concern about the safety and cost of treatment. Since the TORCH study, there has been increasing concern about an increased incidence of infection in people on ICS including pneumonia, TB and atypical mycobacterial infection. ${ }^{9}$ In a large population based study, the risk of pneumonia leading to hospitalisation or death was increased by $69 \%$ in people on ICS. ${ }^{10}$ Other epidemiological studies have found an increased risk of atypical mycobacterial and TB in people on ICS. ${ }^{1112}$ There is also evidence that there may be an increased risk of developing diabetes or for diabetes progressing. ${ }^{13}$ ICS are also expensive, accounting for 3 out of the 10 most expensive drugs to the National Health Service in England. ${ }^{14}$

At the same time, there has been interest in the clinical effects of bronchodilatation with a combination of LABA and LAMA either in free or fixed combinations. These combinations undoubtedly improve lung function more than either component alone but from the limited data available so far, LABA-LAMA combinations also seem to have an effect on exacerbation rates. The mechanism by which bronchodilators reduce exacerbations is likely to be different to that of ICS. Studies to date suggest that exacerbations requiring corticosteroids may be more common in individuals taking LABA-LAMA combinations and antibiotics more commonly needed in those on ICS treatment. Tailoring inhaled therapies in COPD may in the future be guided by exacerbation type.

Nevertheless, there is legitimate interest in the possibility that dual bronchodilator therapy is a viable alternative to ICS containing regime in patients with COPD. Against this background, WISDOM study was conducted to investigate whether ICS could be withdrawn in a controlled, stepwise manner of inhaled glucocorticoids in patients with severe or very severe COPD who were receiving a combination of a LAMA (tiotropium) and a LABA (salmeterol) without increasing the risk of exacerbations. $^{15}$

This was a 12-month, double-blind, parallel-group study which enrolled 2485 patients with a history of exacerbation of COPD. Participants received triple therapy consisting of tiotropium, salmeterol and the ICS fluticasone propionate (500 $\mu \mathrm{g}$ twice daily) during a 6-week run-in period.

Patients were then randomly assigned to one of two treatment strategies. Those in the first group $(n=1243)$ continued to receive tiotropium, salmeterol and fluticasone at the same doses as those used during the run-in period for the whole 52 -week study period. Those in the second group $(n=1242)$ continued to receive tiotropium and salmeterol throughout the 52-week period but had a stepwise reduction in the fluticasone dose every 6 weeks from a total daily dose of $1000-500 \mu \mathrm{g}$, then to $200 \mu \mathrm{g}$ and finally to $0 \mu \mathrm{g}$ (placebo). The primary end point was the time to the first moderate or severe COPD exacerbation. Lung function, health status and dyspnoea were also monitored. There was no difference in the dropout rates between the groups and over $80 \%$ of patients in both groups completed the study.

ICS withdrawal was not associated with either an increased risk of exacerbation (HR 1.06 (95\% CI 0.94 to 1.19)) or increased rate of exacerbations $(0.95 / \mathrm{pt} / \mathrm{y}$ (95\% CI 0.87 to 1.04 ) in the withdrawal group v $0.91 / \mathrm{pt} / \mathrm{y}$ (95\% CI 0.83 to 0.99 ) in the continuation group).

Subgroup analyses did not identify any group of patients at increased risk of an exacerbation after glucocorticoid withdrawal, 
although outcomes in eosinophilic and non-eosinophilic subgroups were not reported. This is an important omission as up to $30 \%$ of people with COPD have increased numbers of eosinophils in sputum and blood and there is evidence that these markers are associated with an increased risk of severe exacerbation ${ }^{16}$ and a better response to corticosteroid therapy. ${ }^{17}$ An additional important limitation is that participants had to have had one or more exacerbation in the preceding year to be included so it could be argued that patients responding well to ICS were less likely to be included.

ICS withdrawal was associated with a fall in $\mathrm{FEV}_{1}$ by $43 \mathrm{~mL}$ compared with the continuation group at the end of the year. There was no difference in dyspnoea scores between the two groups but there was a small but clinically insignificant difference in health status (of 1.22 units on SGRQ scale) favouring the continuation group.

There was no difference in the rates of adverse or serious adverse events. Rates of fatal adverse events were $3.2 \%$ in the withdrawal group and $2.7 \%$ in the continuation group. The incidence of pneumonia was $5.5 \%$ in the withdrawal group and $5.8 \%$ in the continuation group.

What should readers of Thorax make of this new information?

Maintaining or initiating people on ICS solely in an attempt to reduce their risk of having an exacerbation may not be necessary if they are also receiving effective bronchodilator therapy with a LABA and LAMA. Whether ICS are more effective in reducing exacerbations in a subgroup of people with frequent exacerbations ( 2 or more per year) remains to be established. ICS use may be justified if there is evidence of symptomatic or spirometric improvement, but this needs to be balanced against the risk of adverse effects, particularly pneumonia and their cost.

Further studies are needed to investigate whether these findings apply to all people with COPD or are most relevant to particular phenotypes. While randomised controlled trials are often considered the gold standard of research, real life studies confirming or refuting these results including patients who are usually excluded from clinical trials but who make up the majority of the people we see would be helpful. However, one thing is certainly true: conventional wisdom about the benefits of ICS and the dangers associated with their withdrawal has been challenged.

Contributors DMGH wrote the first draft and then JKQ and DMGH both contributed to subsequent drafts.

\section{Funding None.}

Competing interests DMGH has received sponsorship to attend international meetings and honoraria for lecturing, attending advisory boards and preparing educational materials from Almirall, AstraZeneca, Boehringer Ingelheim, Chiesi, GSK, Intermune, MSD, Nycomed and Pfizer. His department has received research funding from AstraZeneca. JKQ is funded on an MRC Population Health Scientist Fellowship. She has also received research funding from GSK, the BLF, has received sponsorship to attend international meetings and honoraria for lecturing and preparing educational materials from Almirall, AstraZeneca and GSK.

Provenance and peer review Not commissioned; internally peer reviewed.

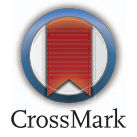

To cite Halpin DMG, Quint JK. Thorax 2014;69:1071-1072.

Published Online First 16 October 2014

Thorax 2014;69:1071-1072.

doi:10.1136/thoraxjnl-2014-206333

\section{REFERENCES}

1 Burge PS, Calverley PM, Jones PW, et al. Randomised, double blind, placebo controlled study of fluticasone propionate in patients with moderate to severe chronic obstructive pulmonary disease: the ISOLDE trial. BMJ 2000;320:1297-303.

2 Kew KM, Mavergames C, Walters JA. Long-acting beta2-agonists for chronic obstructive pulmonary disease. Cochrane Database Syst Rev 2013;10: CD010177.

3 Vogelmeier C, Hederer B, Glaab T, et al. Tiotropium versus salmeterol for the prevention of exacerbations of COPD. N Engl J Med 2011;364:1093-103.
4 Decramer ML, Chapman KR, Dahl R, et al. Once-daily indacaterol versus tiotropium for patients with severe chronic obstructive pulmonary disease (INVIGORATE): a randomised, blinded, parallel-group study. Lancet Respir Med 2013;1: 524-33.

5 Calverley PM, Anderson JA, Celli B, et al. Salmeterol and fluticasone propionate and survival in chronic obstructive pulmonary disease. $N$ Engl I Med 2007;356:775-89.

6 National Institute for Health and Clinical Excellence. Chronic obstructive pulmonary disease: management of chronic obstructive pulmonary disease in adults in primary and secondary care. London: National Clinical Guideline Centre, 2010. [cited September 2014]; http://www.nice.org.uk/guidance/cg101/

7 Jarad NA, Wedzicha JA, Burge PS, et al. An observational study of inhaled corticosteroid withdrawal in stable chronic obstructive pulmonary disease. ISOLDE Study Group. Respir Med 1999:93:161-6.

8 Wouters EF, Postma DS, Fokkens B, et al. Withdrawal of fluticasone propionate from combined salmeterol/ fluticasone treatment in patients with COPD causes immediate and sustained disease deterioration: a randomised controlled trial. Thorax 2005;60:480-7.

9 Suissa S, Patenaude V, Lapi F, et al. Inhaled corticosteroids in COPD and the risk of serious pneumonia. Thorax 2013;68:1029-36.

10 Andréjak C, Nielsen R, Thomsen V, et al. Chronic respiratory disease, inhaled corticosteroids and risk of non-tuberculous mycobacteriosis. Thorax 2013;68: 256-62.

11 Sabroe I, Postma D, Heijink I, et al. The yin and the yang of immunosuppression with inhaled corticosteroids. Thorax 2013;68:1085-7.

12 Brassard P, Suissa S, Kezouh A, et al. Inhaled corticosteroids and risk of tuberculosis in patients with respiratory diseases. Am J Respir Crit Care Med 2011;183:675-8.

13 Suissa S, Kezouh A, Ernst P. Inhaled corticosteroids and the risks of diabetes onset and progression. $A m$ J Med 2010;123:1001-6.

14 Prescribing and Primary Care Services HSCIC. Prescriptions dispensed in the community: England 2002-12. London: Heath \& Social Care Information Centre, 2013.

15 Magnussen H, Disse B, Rodriguez-Roisin R, et al. Withdrawal of inhaled glucocorticoids and exacerbations of COPD. $N$ Engl J Med 2014;371:1285-94.

16 Hospers JJ, Schouten JP, Weiss ST, et al. Asthma attacks with eosinophilia predict mortality from chronic obstructive pulmonary disease in a general population sample. Am J Respir Crit Care Med 1999;160:1869-74.

17 Brightling CE, Monteiro W, Ward R, et al. Sputum eosinophilia and short-term response to prednisolone in chronic obstructive pulmonary disease: a randomised controlled trial. Lancet 2000;356:1480-5. 